\title{
PERANCANGAN DAN IMPLEMENTASI PERANGKAT VISIBLE LIGHT COMMUNICATION SEBAGAI TRANSCEIVER VIDEO
}

\section{DESIGN AND IMPLEMENTATION VISIBLE LIGHT COMMUNICATION DEVICES AS VIDEO TRANSCEIVER}

\author{
Didin Yulian ${ }^{1}$, Denny Darlis ${ }^{2}$, Suci Aulia ${ }^{3}$ \\ ${ }^{1,2,3}$ Prodi D3 Teknik Telekomunikasi, Fakultas Ilmu Terapan, Universitas Telkom \\ 1didin_y@ rocketmail.com, ${ }^{2}$ denny.darlis@tass.telkomuniversity.ac.id, \\ ${ }^{3}$ sucia@ tass.telkomuniversity.ac.id
}

\begin{abstract}
Abstrak
Saat ini lampu penerangan ruangan banyak menggunakan LED (Light Emiting Diode) sebagai komponen utamanya, dan diperkirakan untuk 10 tahun ke depan penggunaan lampu sebagai alat penerangan sudah seluruhnya menggunakan lampu jenis ini. Sementara itu lampu hanya digunakan sebagai alat penerangan ruangan saja. Secara teoritis cahaya dari lampu jenis LED bisa digunakan sebagai media transmisi kecepatan tinggi. Visible Light Communication adalah sistem komunikasi yang menggunakan cahaya tampak sebagai media transmisi menggunakan komponen $L E D$.

Dalam penelitian ini, dikembangkan sebuah perangkat $V L C$ untuk mengirimkan sinyal video analog. Sinyal video dikirimkan melalui $L E D$ di blok transmitter. Kemudian diterima oleh blok penerima, dengan photodiode sebagai penerima informasi. Dalam proses pengirimannya, sinyal video dibagi menjadi dua bagian, yaitu sinyal suara dan video. Hasil penelitian ini, dapat diperlihatkan bahwa sinyal video dapat dikirimkan melalui perangkat $V L C$ dengan jarak $75 \mathrm{~cm}$.
\end{abstract}

\section{Kata kunci : Visible Light Communication, Video, LED, Photodiode}

\begin{abstract}
Currently many room lights using LEDs (Light Emitting Diode) as its main component, and it is estimated for the next 10 years the use of lamps as lighting device have been entirely using this type. While lamp only used for lighting room device. Theoretically lights of an LED type lamp can be used for high speed transmision medium. Visible Light Communication is a communication system that uses visible light as a transmission medium.

In this research, we developed a VLC system to transmit analog video signal. Video signal sent through an LED at transmitter block. Then received by the receiver block, with a photodiode as an information receiver. On transmitting process, video signals are separated into two parts, those are audio and video signals. As the results, it is showed that video signals can be transmitted using VLC device for $75 \mathrm{~cm}$ long.
\end{abstract}

Keyword: Visible Light Communication, LED, Video, Photodiode 


\section{PENDAHULUAN}

Saat ini lampu penerangan ruangan banyak yang menggunakan LED (Light Emiting Diode) sebagai komponen utamanya, dan diperkirakan untuk 10 tahun ke depan penggunaan lampu sebagai alat penerangan sudah seluruhnya menggunakan lampu jenis ini. Sementara saat ini lampu hanya digunakan sebagai alat penerangan ruangan saja. Secara teoritis cahaya dari lampu jenis $L E D$ bisa digunakan sebagai media transmisi kecepatan tinggi. Visible Light Communication adalah sistem komunikasi yang menggunakan cahaya tampak sebagai media transmisi menggunakan komponen $L E D$. Dengan adanya sistem komunikasi ini dimungkinkan pemanfaatan lampu untuk mentransmisikan data. Selain data, sistem komunikasi ini juga dapat dimanfaatkan sebagai pengirim suara, audio, dan video.

Pada penelitian ini, sistem VLC digunakan untuk mengirimkan sinyal video dari sumber DVD player berupa sinyal video komposit dan audio analog dengan jarak antara pengirim dan penerima 1 meter $^{[9][10]}$. Selain sinyal dengan format DVD, sinyal keluaran dari kamera CCTV pun telah dibuat dengan jarak pengirim ke penerima sejauh $50 \mathrm{~cm}^{[11]}$.

Dengan adanya masalah tersebut, maka dalam penelitian ini dibuat suatu sistem yang dapat mengirimkan video dengan menggunakan media cahaya tampak dalam proses pentransmisianya. Sehingga pemanfaatan lampu ruangan bukan hanya digunakan untuk penerangan saja, tetapi juga digunakan untuk mentransmisikan sinyal video.

Tujuan dari penelitian ini adalah mengimplementasikan sistem VLC yang dapat mengirimkan sinyal video dengan jarak sampai 1 meter, sehingga dapat menghemat penggunaan kabel pada sebuah ruangan.

Masalah-masalah yang muncul dalam penelitian ini mengenai cara membedakan antara sinyal audio dan video agar tidak terjadi interferensi antara kedua sinyal tersebut pada saat pengiriman, serta hardware dan modulasi apa yang digunakan telah diselesaikan sebaik mungkin untuk mencapai keberhasilan fungsional sistem.

\section{DASAR TEORI}

\subsection{Sistem Komunikasi Cahaya}

Komunikasi cahaya, juga dikenal sebagai telekomunikasi optik, adalah sebuah komunikasi pada jarak jauh maupun dekat menggunakan cahaya untuk membawa informasi. Hal ini dapat dilakukan secara visual atau dengan menggunakan perangkat elektronik. Komunikasi optik dibedakan menjadi dua yaitu sistem komunikasi optik terpandu (guided optical communication) atau yang lebih dikenal dengan sistem komunikasi serat optik, dan sistem komunikasi optik tak terpandu (unguided optical telekomunication) atau yang lebih sering dikenal dengan sistem komunikasi optik nirkabel.

\subsection{Visible Light Communication ${ }^{[1]}$}

Cahaya tampak (visible light) adalah bentuk di mana radiasi elektromagnetik dengan panjang gelombang dalam kisaran tertentu diinterpretasikan oleh otak manusia. Spektrum yang terlihat mencakup panjang gelombang dari $380 \mathrm{~nm}$ sampai $750 \mathrm{~nm}$. Sistem VLC (visible light communication) adalah media komunikasi data menggunakan cahaya tampak antara $400 \mathrm{THz}$ $(780 \mathrm{~nm})$ dan $800 \mathrm{THz}(375 \mathrm{~nm})$. 


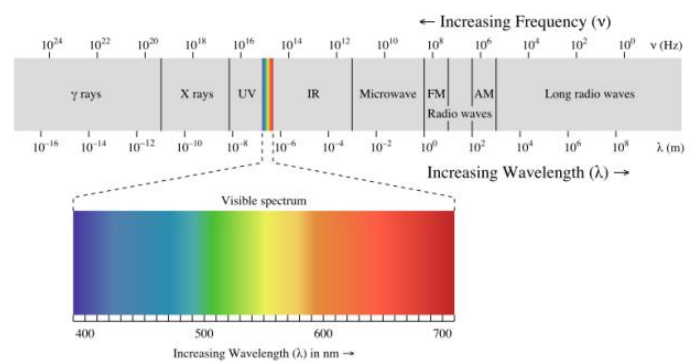

Gambar 1. Spektrum cahaya tampak sebagai bagian dari spektrum gelombang elektromagnetik Sumber : https://en.wikipedia.org/wiki/File:EM_spectrum.svg

\subsection{Composite Video}

Composite video adalah format transmisi video analog yang membawa video definisi standar dengan resolusi 480 atau 576. Sinyal video dikodekan pada satu saluran. Composite video biasanya dalam format standar seperti NTSC, PAL, dan SECAM. Transmisi video ini sering disebut CVBS.

Sinyal dari Composite video ini digabungkan dalam satu saluran dengan kemasan gambar warna, garis, dan sinkronisasi frane. Sinyal video warna adalah kombinasi linear dari pencahayaan gambar, dan subcarrier termodulasi membawa chrominance atau warna informasi, kombinasi warna dan saturasi. Rincian proses encoding bervariasi antara sistem NTSC, PAL dan SECAM.

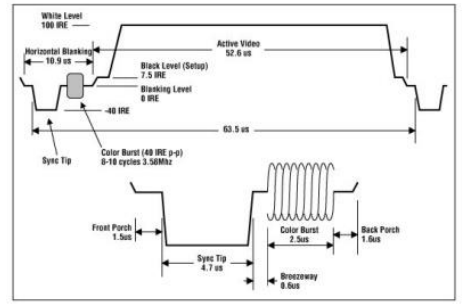

(a)

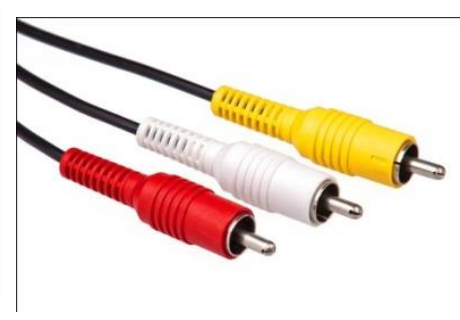

(b)

Gambar 2. (a) sinyal komposit video (b) Konektor RCA

Sumber : https://en.wikipedia.org/wiki/RCA\#/media/File:Composite-cables.jpg

\section{PERANCANGAN SISTEM}

\subsection{Blok Diagram Sistem}

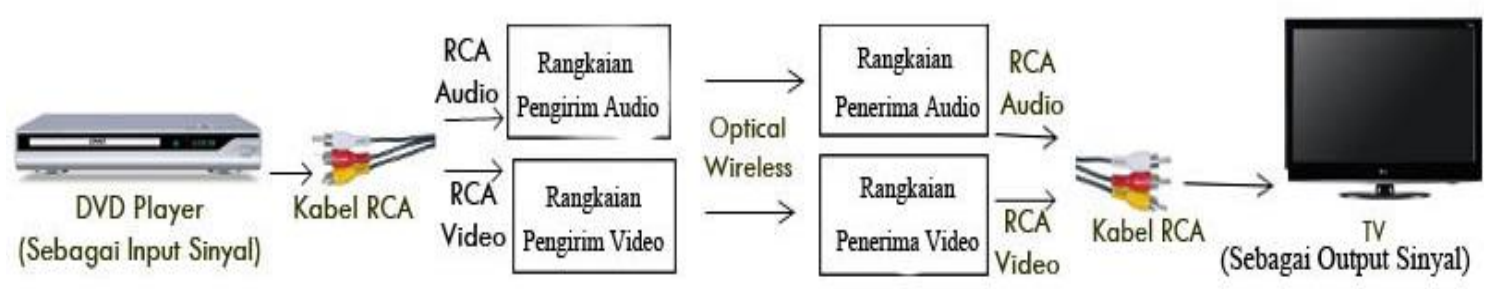

Gambar 3. Gambar sistem keseluruhan

DVD player digunakan sebagai pemutar video atau sebagi sumber sinyal video dan audio. Keluaran dari DVD player disalurkan melalui port RCA menuju rangkaian pengirim. Rangkaian pengirim ini terdiri dari dua, yaitu rangkaian pengirim audio dan rangkaian pengirim 
video. Sinyal audio dan video diolah di rangkaian pengirim, kemudian ditransmisikan melalui cahaya yang dihasilkan oleh $L E D$. Rangkaian penerima terdiri dari dua, yaitu rangkaian penerima audio dan rangkaian penerima video. Cahaya yang dikeluarkan oleh $L E D$ diterima oleh photodiode kemudian diolah di rangkain pengirim untuk dikeluarkan ke TV. TV digunakan sebagai penampil video dan pemutar suara. Sinyal audio dan video yang diterima dan diolah oleh rangkaian penerima disalurkan melalui kabel RCA ke TV. Blok Transmitter dibagi menjadi dua bagian yaitu bagian untuk mengirim sinyal audio dan bagian untuk mengirim sinyal video. sebelum dikirimkan melalui $L E D$ kedua sinyal tersebut akan diolah terlebih dahulu, baik dikuatkan dan ditapis. Sinyal video yang dihasilkan oleh DVD player dikirimkan ke rangkaian transmitter (pengirim) melalui kabel RCA. Sinyal ini diolah sebelum ditransmisikan melalui cahaya oleh $L E D$. Dalam pengolahannya sinyal ini ditapis dan dikuatkan untuk masuk ke rangkaian driver LED.

\subsection{Blok Transmitter Video}

Sinyal video yang dihasilkan oleh DVD player dihubungkan ke rangkaian transmitter (pengirim) melalui kabel RCA. Sinyal ini diolah sebelum ditransmisikan melalui cahaya oleh $L E D$. Dalam pengolahanya sinyal ini dikuatkan lalu masuk ke rangkaian $L E D$ oleh rangkaian seperti di bawah ini.
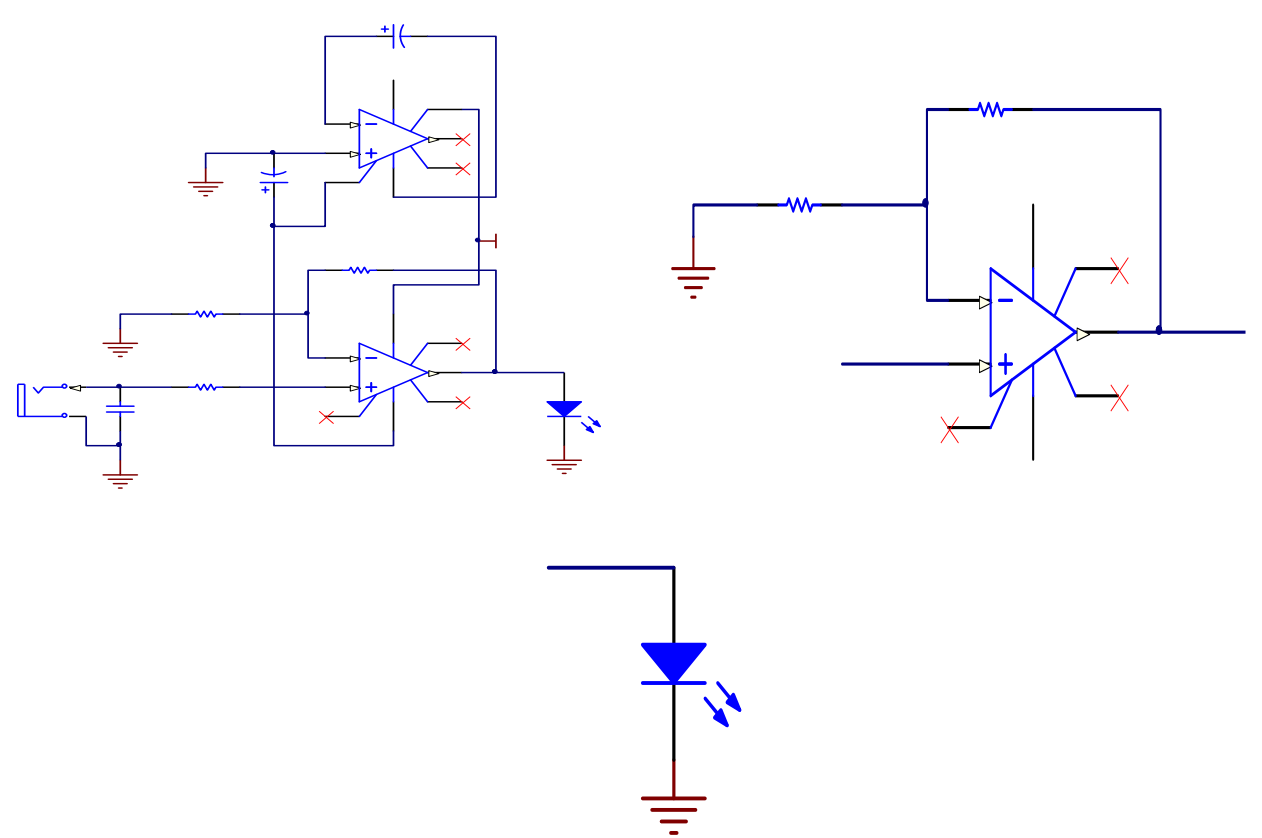

Gambar 4. Rangkaian transmitter, Penguat, dan LED Driver video

\subsubsection{Rangkaian Penguat}

Rangkaian penguat ini menggunakan rangkaian penguat Op-Amp. Op-Amp yang digunakan adalah IC LM 7171. LM 7171 merupakan penguat khusus yang dibuat untuk menguatkan level sinyal video yang lemah. Nilai dari penguatanya adalah 4 kali dari sinyal input, karena nilai dari tegangan input adalah kurang dari $1 \mathrm{~V}$ untuk LED Luxeon aktif ketika minimal $3.4 \mathrm{~V}$ maka,

Av

$$
=(1+\mathrm{R} 3 / \mathrm{R} 2)
$$

$\mathrm{R} 3 / \mathrm{R} 2$

$$
=4-1
$$

$\mathrm{R} 3 / \mathrm{R} 2$

$$
=3
$$




$\begin{array}{ll}\mathrm{R} 3 & =15 \mathrm{~K} \\ \mathrm{R} 2 & =5 \mathrm{~K}\end{array}$

Karena keterbatasan komponen di pasaran, maka resistor (R2) diganti dengan nilai 4K7. Dengan hasil pembagian antara R3 dan R2 mendekati 3 yaitu 3,2.

\subsection{Blok Transmitter Audio ${ }^{[7]}$}

Sinyal audio yang keluar dari DVD player masuk ke rangkaian transmitter (pengirim) melalui kabel RCA. Sinyal ini diolah sebelum ditransmisikan melalui cahaya oleh $L E D$. Dalam pengolahanya sinyal ini di-filter lalu masuk ke rangkaian $L E D$ driver.
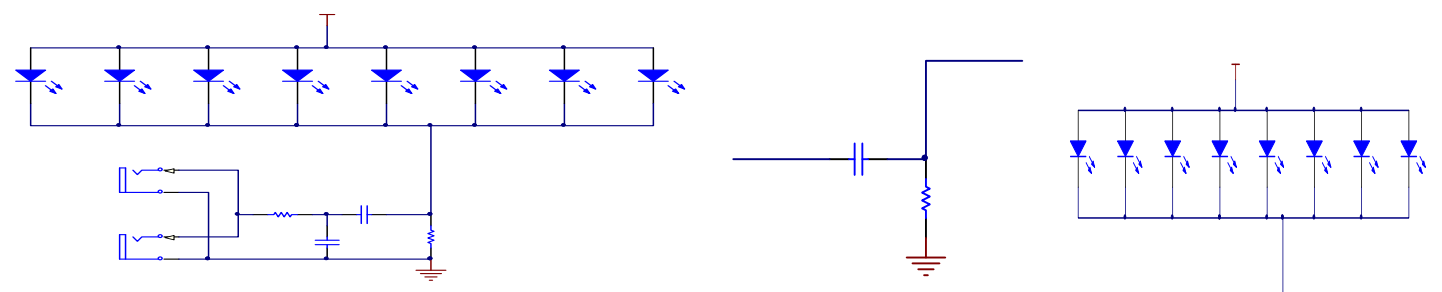

Gambar 5. Rangkaian transmitter, filter HPF, dan LED Driver audio

\subsubsection{Rangkaian Filter}

Filter digunakan untuk menapis sinyal yang tidak diinginkan. Karena sinyal ini merupakan sinyal audio dengan bandwidth sekitar $20 \mathrm{KHz}$, maka digunakan filter LPF untuk menyaring frekuensi rendah dengan frekuensi cut off sebesar $6 \mathrm{KHz}$. Filter yang digunakan merupakan filter $\mathrm{RC}$, dimana haya menggunakan rangkaian Resistor dan kapasitor. Berikut adalah hasil dari perhitungan nilai komponen filter HPF dengan frekuensi cut off sebesar $6 \mathrm{KHz}$ dan Resistor sebesar $75 \Omega$.

$$
\begin{array}{ll}
\mathrm{F} & =1 /(2 \pi \mathrm{RC}) \\
6 & =1 /(2 \pi 75 \mathrm{C}) \\
\mathrm{C} & =330 \mathrm{nF}
\end{array}
$$

Dari perhitungan tersebut, maka didapat nilai Resistor $75 \Omega$, dan kapasitor sebesar 330 $\mathrm{nF}$ dengan bentuk rangkaian seperti pada Gambar 5 .

\subsubsection{Rangkaian LED Driver}

LED driver untuk sinyal audio terdiri dari delapan buah $L E D 1$ watt. Setelah di-filter sinyal audio masuk ke LED driver, untuk kemudian ditransmisikan melalui media transmisi cahaya oleh $L E D$.

\subsection{Blok Receiver Video}

Sinyal cahaya yang dipancarkan oleh LED diterima oleh Photodiode driver yang terdiri dari lima buah photodiode, kemudian dikeluarkan ke monitor tv melalui kabel RCA. Karena sinyal yang diterima sudah mencapai sekitar $1 \mathrm{~V}$, maka tidak diperlukan penguat sebelum dikeluarkan ke monitor. 


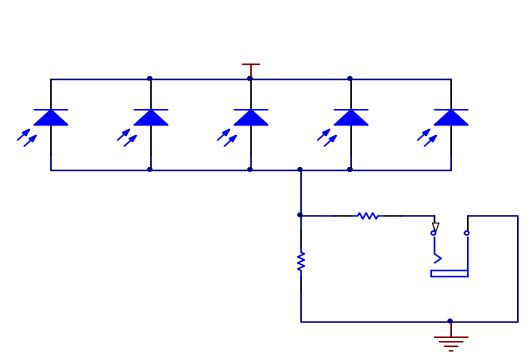

(a)

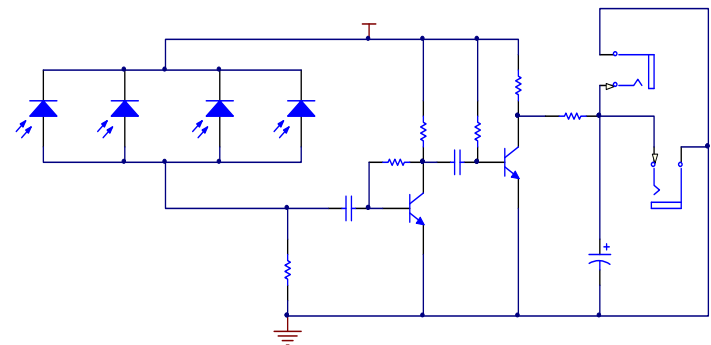

(b)

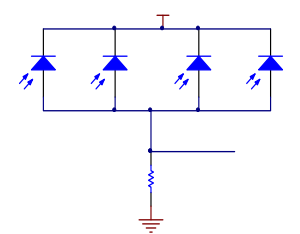

(c)

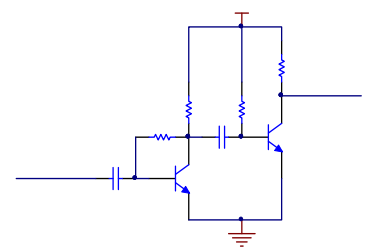

(d)

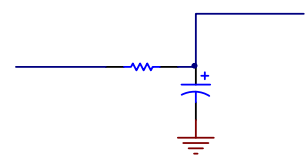

(e)

Gambar 6. (a) Blok receiver video, (b) Rangkaian Receiver audio, (c) photodiode driver, (d) penguat, dan (e) Filter audio

\subsection{Blok Receiver Audio ${ }^{[7]}$}

Sinyal cahaya yang dipancarkan oleh $L E D$ diterima oleh Photodiode driver, kemudian masuk ke bagian rangkaian penguat, setelah dikuatkan sinyal audio tersebuat akan masuk ke bagian filter kemudian disalurkan ke speaker pada TV.

\subsubsection{Photodiode Driver}

Rangkaian dari photodiode yang digunakan sama dengan rangkaian photodiode penerima video. rangkaian potodioda ini terdiri dari empat buah photodiode yang diberikan tegangan terbalik (reserve bias).

\subsubsection{Rangkaian Penguat}

Sinyal audio yang diterima dari photodiode driver kemudian dikuatkan di rangkaian penguat.

\subsubsection{Rangkaian Filter LPF}

Setelah dikuatkan sinyal audio masuk ke rangkaian filter untuk meredam frekuensi tinggi. Setelah di-filter sinyal suara tersebut disalurkan ke speaker pada TV dengan kabel RCA.

\subsection{Cara Kerja Sistem}

Output dari DVD player berupa sinyal elektrik yang disalurkan melalui kabel RCA. Kabel RCA ini membawa sinyal audio dan video. kedua sinyal tersebut masuk ke rangkaian pengirim. Sinyal video akan dikuatkan sebelum dikirimkan oleh LED. Sinyal Audio di-filter sebelum dikirimkan oleh LED.

Setelah dikirimkan sinyal cahaya tersebut akan diterima oleh rangkaian photodiode, sinyal video akan diterima oleh potodiode driver, lalu sinyal tersebut disalurkan oleh kabel RCA menuju monitor TV. Sinyal audio diterima oleh photodiode driver kemudian dikuatkan di rangkaian penguat, setelah dikuatkan disaring oleh rangkaian filter, kemudian dikeluarkan di speaker pada perangkat TV. 


\section{PENGUJIAN}

\subsection{Pengujian Setiap Blok}

Pengujian dilakukan disetiap blok menggunakan osiloskop dengan jarak $75 \mathrm{~cm}$ antara Transmitter dan Receiver. Pada transmitter dilakukan pengujian pada input sinyal video sebelum masuk rangkaian, output sinyal video setelah masuk rangkaian, input sinyal audio sebelum masuk rangkaian, dan output sinyal audio setelah masuk rangkaian. Pada receiver, pengujian sinyal video dilakukan pada output photodiode driver, Sedangkan pengujian sinyal audio pada receiver dilakukan pada output photodiode driver, dan output setelah dikuatkan dan di-filter.

\subsubsection{Pengujian Blok Transmitter}

Pada pengujian ini diukur level tegangan dari keluaran DVD Player, baik sinyal audio maupun video, dan pengukuran sinyal audio dan video setelah masuk ke rangkaian.

\subsubsection{Pengukuran Sinyal Video Pada Masukan Blok Transmitter}

Pengukuran dilakukan keluaran video dari DVD Player. Ini dimaksudkan untuk mengetahui kualitas dari pengiriman sinyal video.

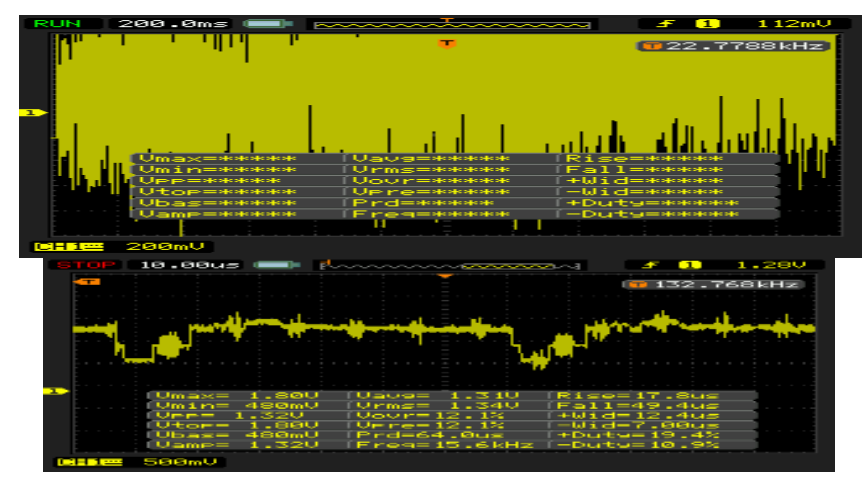

Gambar 7. Sinyal Masukan Audio dan Video pada blok Transmitter

$$
\begin{array}{ll}
\mathrm{V} \mathrm{Max}=1,80 \mathrm{~V} & \text { Periode }=64 \mathrm{us} \\
\mathrm{V} \mathrm{Min}=480 \mathrm{mV} & \text { frekuensi }=15,6 \mathrm{KHz}
\end{array}
$$

Dari gambar diatas, dapat diketahui bahwa keluaran video dari DVD Player adalah bagus, karena memiliki parameter yang sesuai dengan teori bentuk gelombang Composite Video, yaitu dengan Vpp sekitar 1, dan periode 64 us.

\subsubsection{Pengukuran Sinyal Audio Pada Masukan Blok Transmitter}

Pengukuran dilakukan di keluaran audio dari DVD Player. Ini dimaksudkan untuk mengetahui kualitas dari blok transmitter. Pengukuran dengan menggunakan osiloskop untuk mengetahui nilai tegangan.

\subsubsection{Pengukuran Sinyal Video Pada Keluaran Blok Transmitter}

Pengukuran dilakukan di keluaran blok transmitter, tepatnya pada sebelum masuk ke LED. Ini dimaksudkan untuk mengetahui kualitas dari blok transmitter. Perbedaan nilai tegangan antara masukan dan keluaran merupakan ukuran kualitas sinyal audio 

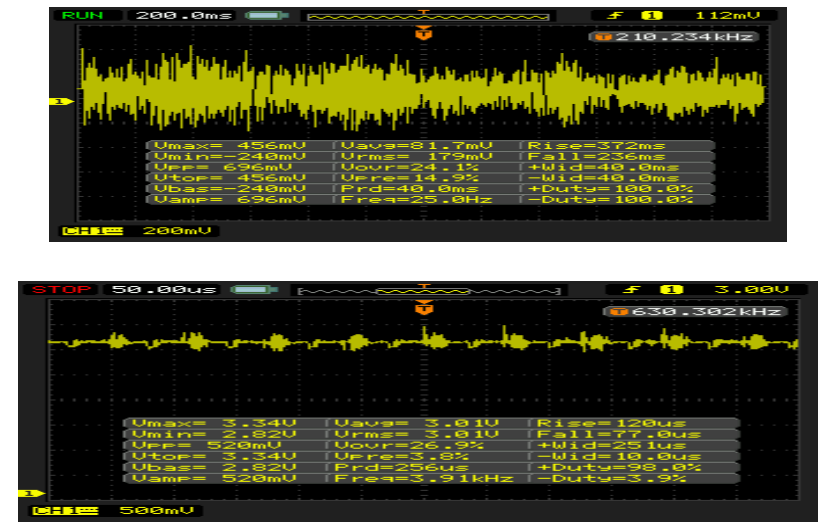

Gambar 8. sinyal keluaran audio dan video sebelum dikirimkan

Setelah masuk ke rangkaian pengirim, level tegangan dari sinyal video bertambah, maka rangkaian pengiriman video sudah bisa dikatakan baik.

\subsubsection{Pengukuran Sinyal Audio Pada Keluaran Blok Transmitter}

Pengukuran dilakukan di keluaran blok transmitter, tepatnya sebelum masuk ke LED. Ini dimaksudkan untuk mengetahui kualitas dari blok transmitter. Karena rangkaian pengirim terdapat filter , maka sinyal keluaranya lebih bagus.

\subsubsection{Pengujian Blok Receiver}

\subsubsection{Pengukuran Sinyal Video Pada Keluaran Photodiode driver}
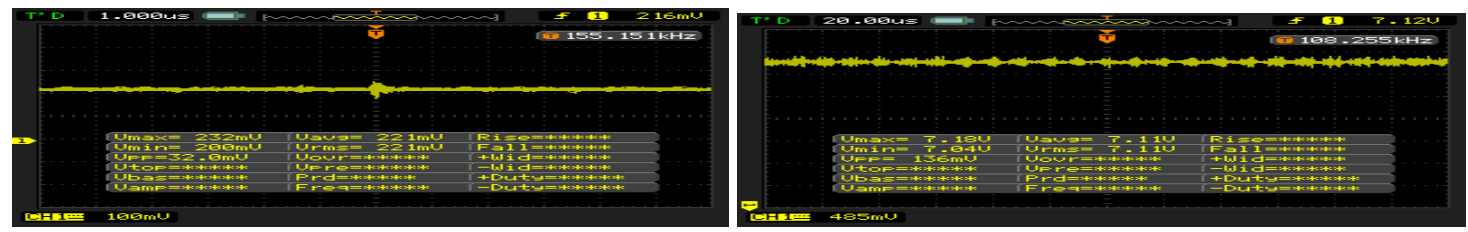

Gambar 9. Sinyal audio dan video yang diterima pada photodiode driver

Pengukuran dimaksudkan untuk mengetahui nilai tegangan pada photodiode driver. Sinyal video dapat diterima oleh photodiode dengan kualitas yang tidak stabil.Tegangan yang terukur adalah merupakan penggabungan sinyal video yang diterima dengan noise dari cahaya sekitar dan sinyal lain yang masuk ke sambungan antara photodiode dan probe pengukur.

\subsubsection{Pengukuran Sinyal Audio Pada Keluaran Photodiode Driver}

Pengukuran dimaksudkan untuk mengetahui nilai tegangan pada photodiode driver, sebelum dikuatkan.

Dari Gambar 9, dapat dilihat kualitas sinyalnya belum sesuai spesifikasi, karena pengaruh noise cahaya luar serta sinyal lain di frekuensi audio, oleh karena itu diperlukan rangkaian penguat dan filter.

\subsubsection{Pengukuran Sinyal Audio Pada Keluaran Blok Receiver}

Pengukuran dimaksudkan untuk mengetahui nilai tegangan pada photodiode driver, setelah dikuatkan. 


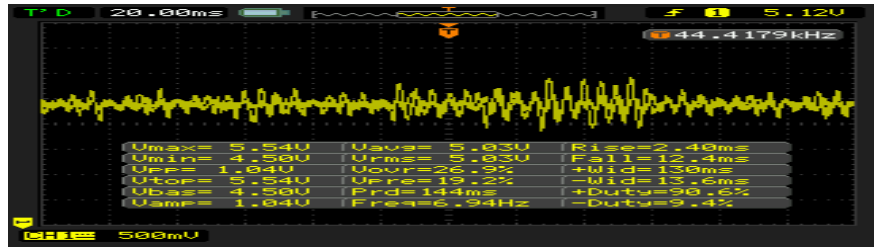

Gambar 10. Sinyal audio yang keluar dari blok receiver

Setelah dikuatkan sinyal audio tersebut memiliki kualitas yang lebih baik dengan tegangan 1,3 V dan bentuk sinyal sinusoidal seperti sinyal audio sebelum ditransmisikan.

\subsection{Pengukuran Blok Sistem Keseluruhan}

Pengukuran dilakukan pada sudut $0^{\circ}, 10^{\circ}, 20^{\circ}, 30^{\circ}, 45^{\circ}$ dengan jarak sampai $75 \mathrm{~cm}$. Dengan 5 kali pengukuran diambil nilai rata-rata jarak yang maksimal untuk menghasilkan kualitas video yang baik dan hanya melakukan percobaan sampai jarak $75 \mathrm{~cm}$ untuk mengetahui nilai daya. Cara perhitungan Daya $(\mathbf{d B})$ adalah $\operatorname{10log}(\mathbf{V} * \mathbf{I})$, dimana $V$ adalah selisih antara tegangan stand by (penerima aktif dan siap menerima informasi) dengan tegangan ketika penerima telah menerima informasi. Dan $\boldsymbol{I}$ adalah selisih antara Arus Stand By (penerima aktif dan siap menerima informasi) dengan arus ketika penerima telah menerima informasi.

Pengukuran dan pengujian dilakukan pada kondisi terang (adanya cahaya matahari dan lampu) jarak dan sudut yang telah ditentukan.

Tabel 1. Data pengukuran nilai tegangan pada sudut $0^{\circ}$

\begin{tabular}{|l|c|c|c|c|c|}
\hline No & Jaxak (cm) & $\begin{array}{c}\text { Tegangan } \\
\text { Video }(\mathbf{m V})\end{array}$ & $\begin{array}{c}\text { Daya Video } \\
\text { (dBm) }\end{array}$ & $\begin{array}{c}\text { Tegangan audio } \\
(\mathbf{m V})\end{array}$ & $\begin{array}{c}\text { Dava audio } \\
\text { (dBm) }\end{array}$ \\
\hline $\mathbf{1}$ & $\mathbf{1 5}$ & 7256 & $\mathbf{3 , 6 7}$ & 5117 & $\mathbf{2 , 9 1}$ \\
\hline $\mathbf{2}$ & 30 & 7241 & $\mathbf{3 , 6 1}$ & 5104 & $\mathbf{3 , 2 0}$ \\
\hline $\mathbf{3}$ & 45 & 7238 & $\mathbf{3 , 5 6}$ & 5111 & $\mathbf{3 , 4 4}$ \\
\hline $\mathbf{4}$ & 60 & 7185 & $\mathbf{3 , 5 0}$ & 5112 & $\mathbf{3 , 5 5}$ \\
\hline $\mathbf{5}$ & 75 & 7180 & $\mathbf{3 , 4 0}$ & 5099 & $\mathbf{3 , 6 3}$ \\
\hline
\end{tabular}

Tabel 2. Data pengukuran nilai tegangan pada sudut $30^{\circ}$

\begin{tabular}{|l|c|c|c|c|c|}
\hline No & Jaxak (cm) & $\begin{array}{c}\text { Tegangan } \\
\text { Video }(\mathbf{m V})\end{array}$ & $\begin{array}{c}\text { Daya Video } \\
\text { (dBm) }\end{array}$ & $\begin{array}{c}\text { Tegangan audio } \\
\text { (mV) }\end{array}$ & $\begin{array}{c}\text { Daxa audio } \\
\text { (dBm) }\end{array}$ \\
\hline $\mathbf{1}$ & $\mathbf{1 5}$ & 0 & - & 0 & - \\
\hline $\mathbf{2}$ & 30 & 0 & - & 0 & - \\
\hline $\mathbf{3}$ & 45 & 0 & - & 0 & - \\
\hline $\mathbf{4}$ & 60 & 0 & - & 0 & - \\
\hline $\mathbf{5}$ & 75 & 0 & - & 0 & - \\
\hline
\end{tabular}

Tabel 3. Data pengukuran nilai tegangan pada sudut $45^{\circ}$

\begin{tabular}{|l|c|c|c|c|c|}
\hline No & Jarak (cm) & $\begin{array}{c}\text { Tegangan } \\
\text { Video }(\mathbf{m V})\end{array}$ & $\begin{array}{c}\text { Daya Video } \\
\text { (dBm) }\end{array}$ & $\begin{array}{c}\text { Tegangan audio } \\
(\mathbf{m V})\end{array}$ \\
\hline $\mathbf{1}$ & $\mathbf{1 5}$ & 0 & - & 0 & $\begin{array}{c}\text { Dava audio } \\
\text { (dBm) }\end{array}$ \\
\hline $\mathbf{2}$ & 30 & 0 & - & 0 & - \\
\hline $\mathbf{3}$ & 45 & 0 & - & 0 & - \\
\hline $\mathbf{4}$ & 60 & 0 & - & 0 & - \\
\hline $\mathbf{5}$ & 75 & 0 & - & 0 & - \\
\hline
\end{tabular}

Dalam penelitian ini, dilakukan pengukuran sesuai parameter yang ditentukan. Pengukuran alat ini, di lakukan percobaan sebanyak 5 kali dengan kondisi jarak dan sudut yang berbeda. Pada pengukuran kondisi waktu gelap, semakin jauh jarak semakin kecil nilai daya. 
Dari hasil percobaan ini, semakin jauh jarak, serta semakin besar sudut antara Transmitter dan Receiver maka semakin kecil daya yang dihasilkan dan dapat memyebabkan sinyal informasi gagal diterima.

Kesimpulan pengujian dari faktor jarak dan sudut saat kondisi gelap

1. Video dapat diterima hanya pada sudut $<=20^{\circ}$

2. Audio dapat diterima hanya pada sudut $<=20^{\circ}$

\subsection{Pengukuran Parameter Telekomunikasi (Delay)}

Pengukuran dilakukan pada jarak $75 \mathrm{~cm}$ dengan sudut $0^{\circ}, 10^{\circ}, 20^{\circ}$ dalam kondisi gelap dan terang karena apabila sudut melebihi $20^{\circ}$ sinyal audio dan video tidak dapat diterima oleh blok penerima. Hal ini dimaksudkan untuk mengetahui delay pada kondisi maksimal di jarak 75 $\mathrm{cm}$. Pengukuran menggunakan osciloscope dimana delay dihitung dari selisih antara periode sinyal yang diterima dengan sinyal yang dikirim.

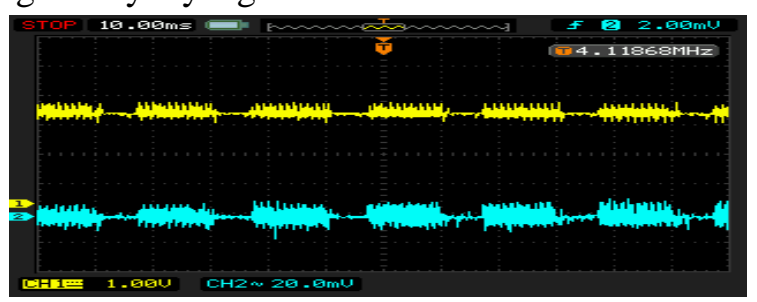

Gambar 11. sinyal video tx (kuning) rx (biru \}

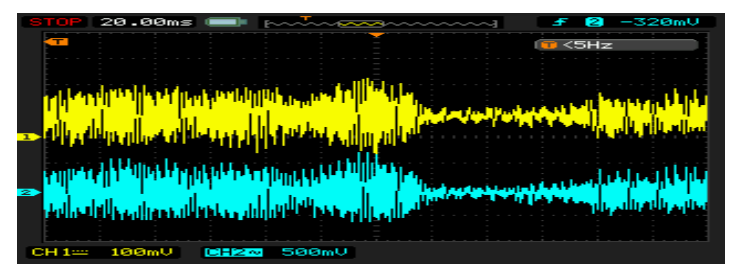

Gambar 12. sinyal audio tx (kuning) rx (biru) setelah di zoom

Gambar 11 menunjukan bentuk sinyak dari audio sebelum diperbesar (zoom in) dimana yang berwarna kuning adalah bentuk sinyal saat dikirim, dan biru adalah bentuk sinyal yang diterima. Gambar 12 menunjukan bentuk sinyal audio yang telah diperbesar. Dari kedua sinyal tersebut nilai delay dapat diketaui. Berikut adalah hasil pengukuran delay audio dan video.

Tabel 4 .Data pengukuran delay

\begin{tabular}{|c|c|c|c|c|c|}
\hline \multirow[b]{2}{*}{ No } & \multirow[b]{2}{*}{ sudut } & \multicolumn{2}{|c|}{ Gelap } & \multicolumn{2}{|c|}{ Terang } \\
\hline & & $\begin{array}{c}\text { Video } \\
\text { (ps) }\end{array}$ & $\begin{array}{l}\text { Audio } \\
\text { (ps) }\end{array}$ & $\begin{array}{c}\text { Video } \\
\text { (ps) }\end{array}$ & $\begin{array}{l}\text { Audio } \\
\text { (ps) }\end{array}$ \\
\hline 1 & $0^{\circ}$ & 100 & 20 & 120 & 30 \\
\hline 2 & $10^{\circ}$ & 120 & 30 & 150 & 40 \\
\hline 3 & $20^{\circ}$ & 180 & 50 & 250 & 60 \\
\hline
\end{tabular}

\section{KESIMPULAN}

1. Video dapat dikirim dengan menggunakan sistem Visible Light Communication pada jarak maksimal $75 \mathrm{~cm}$.

2. Kualitas suara dan video akan semakin menurun apabila jarak lebih dari $75 \mathrm{~cm}$ dan sudut lebih dari $25^{\circ}$. Hal tersebut terjadi karena penurunan tegangan yang disebabkan karena sinyal yang dikirim tidak dapat diterima dengan sempurna.

3. Sudut yang terbentuk dari Transmiter ke Receiver mempengaruhi jarak pengiriman video. Sudut $0^{\circ}$ merupakan sudut terbaik untuk pengiriman video. 


\section{Daftar Pustaka:}

[1] Arnon, S., Visible Light Communications, Cambridge Press, 2015

[2] O'Brien, Dominic Dan K, Marcos. 2005. Short-range Optical Wireless Communication. Wireless World Research Forum. Volume 9, no.3.

[3] Zeng, Lubin, O'Brien, Dominic, Le Minh, Hoa, Lee, Kyungwoo, Jung, Daekwang dan Oh, YunJe. 2008. Improvement of date rate by using equalization in an indoor Visible Light Communication system. 2008 4th IEEE International Conference on Circuits and Systems for Communications. IEEE, Piscataway, pp. 678-682. ISBN 978-1424417070

[4] J,Rani,P, Chauhan, R, Tripathi. 2012. Li -Fi (Light Fidelity)-The future technology In Wireless communication. International Journal of Applied Engineering Research. ISSN 0973-4562 Vol.7 No.11

[5] T, Komine DAN M, Nakagawa. 2004. Fundamental Analysis for Visible-Light Communication System Using LED Lights. IEEE Transactions on Consumer Electronics, Vol. 50, no. 1, pp. 100-107.

[6] S,Iwasaki, C,Premachandra, T,Endo, T,Fujii, M,Tanimoto, dan Y,Kimura. 2008. Visible light road-to-vehicle communication using high-speed camera. IEEE IVS'08, June 2008, Eindhoven, Netherlands, pp. 13-18.

[7] R,Gusti Iqbal. Denny Darlis, Hasanah Putri, Perancangan dan Implementasi Visible Light Communication Untuk Komunikasi Suara. 2014, Proyek Akhir D3 Teknik Telekomunikasi, Universitas Telkom.

[8] Trihantoro, Des Hariangga, Denny Darlis, et.al IMPLEMENTASI VISIBLE LIGHT COMMUNICATION (VLC) UNTUK PENGIRIMAN TEKS, Prosiding Seminar Nasional Teknologi Terapan, Sekolah Vokasi UGM, 2014 (Nasional tidak terakreditasi DIKTI) ISBN: 978-602-1159-06-4

[9] S, Do Ky, C, Eun Byeol, L, Chung Chiu. Demonstration of Visible Light Communication link for audio and video transmission. Departement of Electrical Engineering, Chosun University, Gwangju, Korea. 2012

[10] J, Rufo, F, Delgado, C, Quintana, A, Perera, J, Rabadan, dan R, Perez-Jeliamez. Visible Light Communication For Optical Video Transamission. Photonic and communication, Technological Center For Innovations in Communications (CeTIC), Universaidad de Las Plamas de Gran Canaria, Spain. 2009

[11] P, Lih Chieh. A Fully Integrated Audio Video and Data VLC Transceiver System for Smartphones and Tablets. Nanyang Technologycal University, School of Electrical Engineering. Singapore. 2013. 